ORIGINAL ARTICLE

AFRICAN JOURNAL OF CLINICAL AND EXPERIMENTAL MICROBIOLOGY

MAY 2011

ISBN 1595-689X VOL 12 No.2

AJCEM/200704/2801

http://www.ajol.info/journals/ajcem

COPYRIGHT 2011

AFR. J. CLN. EXPER. MICROBIOL. 12(2): 49- 53

\title{
Binding to CSA receptor is associated with asymptomatic and mild malaria: a preliminary study using $P$.falciparum field isolates from Sudan
}

\author{
Hassan DA ${ }^{*}$, Mohamed HS${ }^{2}$, El-Hussein $\mathrm{AM}^{1}$, Ibrahim $\mathrm{ME}^{2}$ and Abdulhadi $\mathrm{NH}^{3}$ \\ ${ }^{1}$ Central laboratory, Ministry of science and technology, Khartoum, Sudan. \\ ${ }^{2}$ Institute of endemic diseases, University of Khartoum, Khartoum, Sudan. \\ ${ }^{3}$ College of Pharmacy, The National Ribat University, Khartoum, Sudan.
}

\begin{abstract}
*Correspondence: Dina A. Hassan, Central Laboratory, Ministry of science and technology, Khartoum, Sudan. E-mail:
\end{abstract} dinaibrahim6@gmail.com

\begin{abstract}
:
Malaria imposes great socio-economic burden on humanity, and afflicts approximately 90 countries and territories in the tropical and subtropical regions, almost one half of them are in Africa, South of Sahara. Sequestration of parasitized erythrocytes within the small vessels of vital organs is a key event in the pathogenesis of malaria and responsible of virulence of Plasmodium falciparum parasite. To find out whether the ability of infected red blood cells (IRBCs) to adhere to a specific receptor is a risk factor for developing severe clinical manifestation of the disease, in-vitro cytoadhesion and inhibition experiments were performed on field isolates obtained from five symptomatic and five asymptomatic patients inhabiting Gazira State, Central Sudan. The results showed significant lower levels $(p<0.02)$ of cytoadhesion among asymptomatic compared to symptomatic patients. Percent inhibition by FA6-152, a monoclonal antibody for CD36, was comparable between the two study groups. However, the inhibition by CSA protein was less among symptomatic compared to asymptomatic patients. These results shed light on possible role of CSA receptors expressed on endothelial cells in ameliorating the events associated with the severe phenotype of the disease.
\end{abstract}

\section{INTRODUCTION}

Plasmodium falciparum malaria remains the major cause of death in Sub Saharan Africa, mostly among children below the age of five years. According to the mechanical hypothesis which was first proposed in 1894 by Marchiafava and Bignami [cited by 1], the pathogenicity of $P$. falciparum results from its unique ability to adhere to capillary and postcapillary venular endothelium during the second half of the 48-h erythrocytic life cycle, a process that is called cytoadherence. The resulting sequestration of infected red blood cells (IRBCs) leads to alterations in microcirculatory blood flow, metabolic dysfunction, and, as a consequence, many of the manifestations of severe falciparum malaria [2]. It has been reported that patients who die in the acute phase of falciparum malaria have intense sequestration of erythrocytes containing mature forms of the parasite in the microvasculature of vital organs [reviewed by 3].

In vitro models have shown that erythrocytes parasitized with mature stage of P.falciparum may adhere to receptors found on the endothelial cell surface. A key question is whether the ability of IRBCs to adhere to a specific receptor is a risk factor for developing severe clinical manifestation of the disease. Several studies among different populations were carried out to investigate the correlation between binding to specific host receptor and disease outcome. However, results obtained from these studies were considerably variable. A study among Malawian children [4] has investigated the binding of purified receptors CD36 (cluster of differentiation 36), ICAM-1 (intercellular adhesion molecule), CSA (chondroitin sulphate A) and thrombmodulin (TM) to fresh parasite isolates cultured to trophozoite stage from children with uncomplicated and severe malaria. Eighty five percent of all isolates bound to CD36, and 56\% bound to ICAM-1. Fewer bound to CSA $(27 \%)$ or TM (15\%). However, after standardizing for parasitemia, parasite isolates from children with uncomplicated disease bound at higher levels to all receptors, significantly so for ICAM-1 and CD36. Conversely, a similar study at Kilifi on the Kenyan coast using cryopreserved and thawed isolates, has reported that the binding to ICAM-1 was highest among isolates from cerebral non-anaemic malaria patients whereas CD36 binding was slightly elevated among non-severe cases [5]. The study also reported that very few isolates could bind to VCAM-1 and none to E-selectin. Another study among Gambian children with falciparum malaria using monoclonal antibodies also showed that CD36 and ICAM-1 antigens were the major mediators of adhesion of IRBCs to vascular endothelium [6]. Cytoadherence characteristics were also studied among Thai patients [7] with complicated and noncomplicated malaria using in vitro model of human lung endothelial cells (HLEC). According to this study, cytoadherence was significantly associated 
with malaria severity and in consistence to previous studies CD36 was the main receptor in patients with uncomplicated malaria while ICAM-1 and CSA were major receptors among those with complicated malaria. Moreover, VCAM-1 and E-selectin played minor role in cytoadhesion among both groups. In a study conducted in non-immune travellers [8], it has been shown that IRBCs from severe malaria isolates appeared to adhere more frequently and/or strongly to ICAM-1 and CD36 in comparison with uncomplicated cases.

Recent attempts to explain the variable pathology seen in malaria stated that apposition of IRBCs activate signalling pathways. This is dependent, at least in part, on the cytoadherence characteristics of the invading isolate, such that the avidity of the IRBC for the receptor on host endothelium is proportional to the level of activation of the signalling pathways [9]. It has also been proposed that the balance between positive and negative regulation of genes involved in inflammation and cell death, by IRBCs and TNF will contribute to endothelial pathology during malarial infection [9].

The current study is a preliminary study intended to define host endothelial cell receptors favoured by the field isolates from Gazira state, Central Sudan and the impact of adherence to these receptors on the pathogenicity of malaria.

\section{SUBJECTS AND METHODS}

Subjects included in this study were inhabitants of Wadmadani city, Gazira State, central Sudan or its suburbs, an area characterized by seasonal malaria transmission. The experiment included five field isolates of P.falciparum from symptomatic children attending Wadmadani paediatric hospital and five isolates from asymptomatic children during screening for P.falciparum in a primary school in the area. Diagnosis of malaria was confirmed by immuonochromatographic rapid test (Hexagon Malaria CombiTM; Human, Wiesbaden, Germany) and Giemsa stained blood films. Classification of cases was based on clinical signs, and laboratory findings of malaria at the time of presentation.

One and half mililiters of venous blood were drown in citrate Vacutainer ${ }^{\circledR}$ tube (BD, Franklin Lakes, NJ) from each child enrolled after obtaining a signed consent form by parents or guardians. The study protocol was approved by the Ethical Committee of the institute of endemic diseases, University of Khartoum.

\section{Human lung endothelial cells (HLEC) culture}

HLECs are used in this experiment (gift from Laboratoire de Parasitologie Expe'rimentale, Faculte' de Me'decine, Universite' de la Me'diterrane'e, Marseille, France). The cells are characterized by expressing CSA, CD36 and ICAM1 receptors. Cells were cultured in DME/F-12 media (Sigma, USA) at a density of 3,000 Cells/well in 12- well IFA slides for 24 to 48 hours under standard conditions to reach confluence as described by [10]. Maturation and enrichments of parasite isolates Field isolates were cultured as previously described [11] in RPMI 1640 medium supplemented with $0.2 \%$ sodium bicarbonate, $0.25 \%$ AlbuMax, $0.6 \%$ hepes and $10 \mu \mathrm{g} / \mathrm{ml}$ gentamicin and incubated in a candle jar at $37^{\circ} \mathrm{C}$. Cultures were harvested after $48-60$ hours when parasites were mostly at the mature stage of schizonts and trophozoites. Erythrocytes Infected with mature stages were enriched by gelatin sedimentation technique described by [12] and the suspension of each isolate was used in duplicate static cytoadhesion and inhibition assays with HLECs. Parasitemia after gelatin sedimentation was adjusted to $1.5 \times 10^{10} \mathrm{IRBCs} / \mathrm{ml}$.

\section{Static cytoadhesion assays}

Static cytoadhesion assays were carried out in duplicate for each sample on 12-well IFA slides on which HLECs had been cultured to confluence [10] Briefly, the cell culture media was aspirated carefully from the edge of each well and $20 \mu \mathrm{l}$ of (IRBCs) suspension prepared by gelatin sedimentation and $20 \mu \mathrm{l}$ of RPMI 1640 media supplemented with $10 \mu \mathrm{g} / \mathrm{ml}$ gentamicin were added to each well. The IRBCs were allowed to cytoadhere to the confluent HLECs for $2 \mathrm{~h}$ at $37^{\circ} \mathrm{C}$. Unattached IRBCs were removed by washing with RPMI 1640 media, and the cells were fixed for 1 hour with $2.5 \%$ glutaraldehyde (Sigma, USA). Number of IRBCs adhering to HLECs was counted under inverted microscope in four fields for each well (Fig 1). The result expressed as IRBCs $/ \mathrm{mm}^{2}$ was calculated as follows:

IRBCs $/ \mathrm{mm}^{2}=$ number of IRBCs in each field/area of field.

Average IRBCs $/ \mathrm{mm}^{2}=$ Sum IRBCs $/ \mathrm{mm}^{2}$ of the four fields/4.

\section{Cytoadhesion inhibition assays}

Soluble CSA at a concentration of $100 \mu \mathrm{g} / \mathrm{ml}$ (Fluka; 27042) and FA6-152 anti-CD36 monoclonal antibody at a concentration of $5 \mathrm{mg} / \mathrm{ml}$ were used to inhibit cytoadhesion to CSA and CD36 receptors respectively. Briefly, $20 \mu \mathrm{l}$ IRBCs suspension from each isolate were incubated with HLECs in the presence of either $20 \mu \mathrm{l}$ of soluble CSA or anti-CD36 $\mathrm{mAb}$. IRBCs $/ \mathrm{mm}^{2}$ after inhibition were calculated by the same procedure used for cytoadhesion assays (Fig 2,3). The percent inhibition of cytoadhesion was calculated using the following equation:

$\%$ inhibition $=1$-(average IRBCs $/ \mathrm{mm}^{2}$ after inhibition) / average IRBCs $/ \mathrm{mm}^{2}$ without inhibition) * 100 .

Mann-Whitney tests were used to evaluate the statistical significance of differences.

\section{RESULTS}

Average cytoadherence counted as IRBCs/mm2 was significantly higher among symptomatic 
patients compared to asymptomatics $(p<0.02)$, (table $1)$. Inhibition of cytoadhesion using soluble CSA protein reduced the cytoadhesion by $5.04 \%$ and $40.8 \% \quad(\mathrm{p}<0.08) \quad$ among symptomatic and asymptomatic patients respectively. On the other hand, \% inhibition by FA6-152 anti-CD36 mAb was comparable between the two study groups (Fig 4).

\section{TABLE 1: LEVELS OF CYTOADHESION AND INHIBITION OF CYTOADHESION BY CSA PROTEIN AND EA6-152}

ANTI CD36 MAB AMONG THE STUDY GROUPS

\begin{tabular}{|c|c|c|c|}
\hline Parameter (average $\pm S D$ ) & Symptomatic & Asymptomatic infection & p-value \\
\hline Cytoadhesion (IRBC/mm2) & $480.20 \pm 127.0$ & $136.08 \pm 21.0$ & $p<0.02^{*}$ \\
\hline $\begin{array}{l}\text { \% inhibition by CSA } \\
\text { protein }\end{array}$ & $5.04 \pm 2.3$ & $40.80 \pm 16.6$ & $p<0.08$ \\
\hline \%inhibition by FA6-152 & $72.60 \pm 6.8$ & $72.50 \pm 9.6$ & $p<0.7$ \\
\hline
\end{tabular}

*Statistically significant difference; $p<0.05$

FIGURE 1: CYTOADHESION OF AN ISOLATE FROM ASYMPTOMATIC PATIENT (A) AND SYMPTOMATIC PATIENT (B)

IRBC
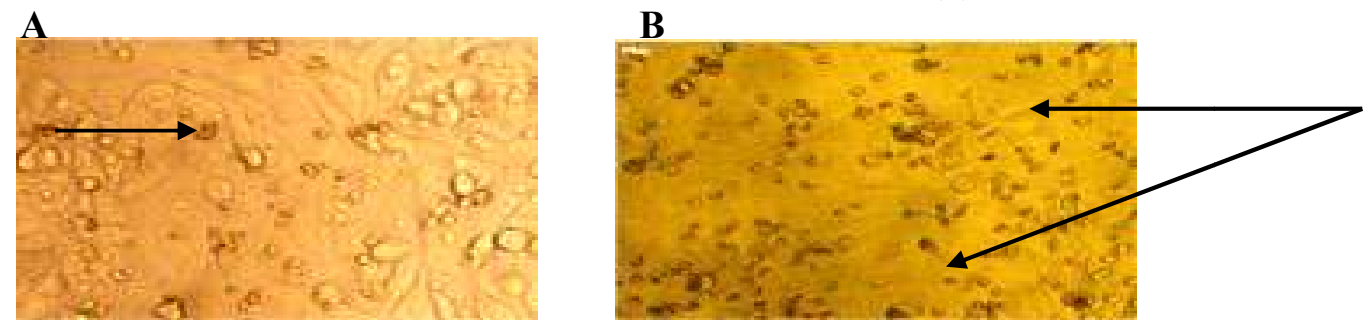

HLEC

FIGURE 2: INHIBITION OF CYTOADHESION BY SOLUBLE CSA PROTIEN OF AN ISOLATE FROM ASYMPTOMATIC PATIENT (A) AND SYMPTOMATIC PATIENT (B)
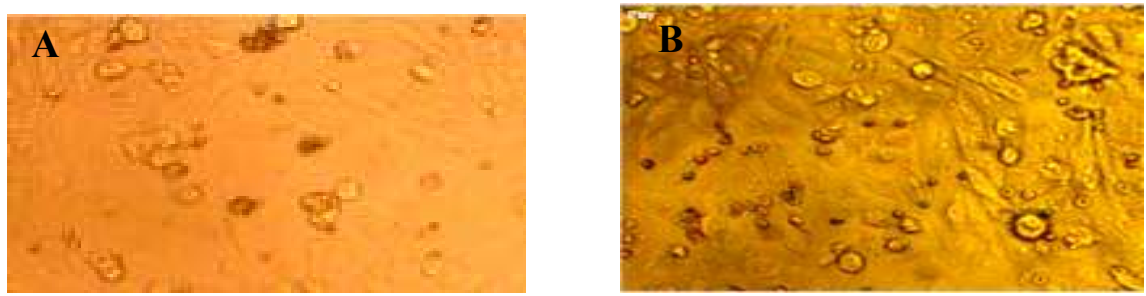

FIGURE 3: INHIBITION OF CYTOADHESION BY FA6-152 ANTI CD36 MAB OF AN ISOLATE FROM ASYMPTOMATIC PATIENT (A) AND SYMPTOMATIC PATIENT (B)
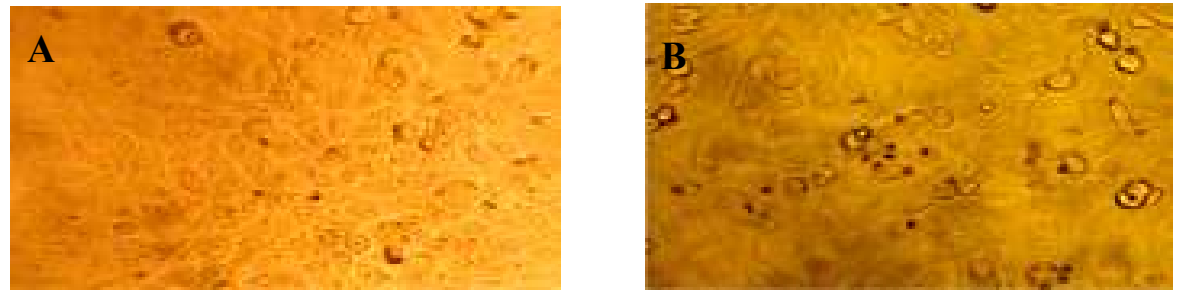

\section{HLEC monolayer}


FIG 4: PERCENTAGE INHIBITION OF CYTOADHESION BY FA6-152 AND CSA PROTEINS IN SYMPTOMATIC AND ASYMPTOMATIC PATIENTS.

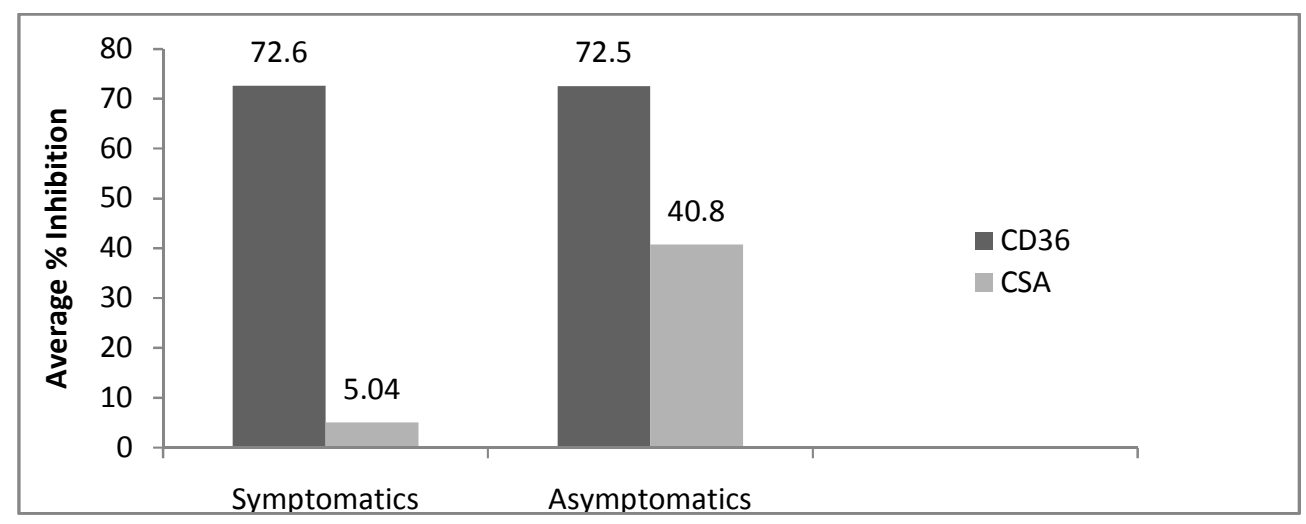

\section{DISCUSSION}

In human $P$. falciparum malaria infection, IRBCs either sequester or are removed from the circulation primarily by the spleen. The balance between splenic clearance and sequestration, which allows the parasite to evade the immune system, is a major determinant of the rate of increase and magnitude of the infecting parasite burden. Within this paradigm, pathogenicity is proportional to the size of the sequestered parasite burden and the pattern of vital organ sequestration [reviewed by 3]. A key question is whether the ability of IRBCs to adhere to a specific receptor is a risk factor for developing severe clinical manifestation of the disease. In an attempt to answer this question and to determine the relative importance of CD36 and CSA receptor molecules for wild-type parasites among Sudanese, we have used static binding assays of IRBCs taken directly from the peripheral blood of patients with falciparum malaria to HLECs.

Our results confirmed the correlation between cytoadhesion and disease severity. Indeed, the level of cytoadhesion increased by 3.5 folds among symptomatic compared to asymptomatic patients. Inhibitions assays were carried out to evaluate the contribution of each of the selected receptors to the level of cytoadherence. Our results showed that $(91.7 \%)$ of all tested isolates bound to CD36 receptor. This is consistent with previous studies using wild-type isolates among Thai [7], Malawian [4] and Kenyan [5] patients with severe and uncomplicated malaria. All isolates from Thai and Kenyan patients and $85 \%$ of Malawian patients bound to purified CD36 receptor. Similar results were also obtained with lab adapted strains [12]. However, the absence of significant difference in the percent cytoadhesion inhibition between the two study groups $(p<0.7)$ indicates lack of correlation between CD36 binding and clinical severity of the disease. This is in agreement with previous studies reported among Kenyan children [5]. In contrast to our results, CD36 was found to be associated with uncomplicated malaria among Thai patients [7] and
Malawian children [4]. It was suggested that this negative association between CD36 binding and disease severity might be due to the sequestration of parasites in less harmful parts of the body. Interestingly, a study among non-immune travelers reported that IRBCs from severe malaria appeared to adhere more frequently and/or strongly to ICAM-1 and CD36 in comparison with uncomplicated cases [8]. The contradicting reports on the association between CD36 binding and severity of malaria among the different populations might be attributed, at least partially, to polymorphism in the gene encoding CD36 protein. It has been reported that African populations contain an exceptionally high frequency of mutations in CD36 [13]. To our knowledge no studies were conducted so far on CD36 polymorphism among Sudanese population and its relation to malaria severity.

On the other hand, the binding of IRBCs to CSA receptors was quite variable among the different isolates. Although CSA receptor is closely associated with placental malaria where it is expressed on syncytiotrophoblasts that line the placental intervillous space, some reports pointed to the occurrence of CSA binding variants in nonpregnant individuals [14].The restriction of the CSA specific phenotype to the placenta is ruled out by the desequestration of IRBCs obtained when $P$. falciparum infected non-pregnant Saimari sciureus monkeys are injected with CSA. The specificity of this desequestration demonstrates that IRBCs are able to cytoadhere to CSA in the microvasculature of non-pregnant animals of this primate species, as well as in the placenta [10].

According to our data, only $58.3 \%$ of all study isolates adhere to CSA compared to $91.7 \%$ adherence to CD36 receptors. The reduced adherence to CSA receptors compared to CD36 is in agreement with previous studies among Malawian children [4] and Thai patients [7]. Our results 
showed that the average percent cytoadhesion inhibition by CSA protein was higher among the asymptomatic group. However, the difference was not statistically significant probably due to the small sample size. In agreement with our results, a nonsignificant increase in CSA binding among Malawian children with uncomplicated malaria was reported [4]. In contrast, a higher percent of cytoadhesion inhibition by CSA antibodies among complicated malaria cases compared to uncomplicated ones was reported among Thai patients [7].

On conclusion, this study shed light on the importance of CSA as a putative receptor for uncomplicated or asymptomatic malaria among Sudanese in the study area and may protect against

\section{EFERENCES}

1. Henri C. van der Heyde, Nolan J, Combes V, Gramaglia I, Grau GE. A unified hypothesis for the genesis of cerebral malaria: sequestration, inflammation and hemostasis leading to microcirculatory dysfunction.Trends in parasitology 2006;22(11):503-508.

2. Toure FS, Boyer OO, Ndong JM, NdongAtome GR, Bisvigou U, Mazier D and Bisser S. Cytoadherence and genotype of Plasmodium falciparum strains from symptomatic children in Franceville, southeastern Gabon. Clinical Medicine \& Research 2007; 5(2):106-113.

3. Ho $\mathbf{M}$ and White NJ. Molecular mechanisms of cytoadherence in malaria. Am J Physiol 1999; 276:C1231-C1242.

4. Rogerson J, Tembenu R, Dobano C, Plitt S, Taylor TE, Molyneux M. Cytoadherence characteristics of Plasmodium falciparuminfected erythrocytes from Malawian children with severe and uncomplicated malaria. Am. J. Trop. Med. Hyg. 1999; 61(3): 467-472.

5. Newbold C, Warn P, Black G, Berendt A, Craig A, et al. Receptor-specific adhesion and clinical disease in Plasmodium falciparum. Am. J. Trop. Med. Hyg. 1997; 57(4) 389:398

6. Cooke BM, Morris-Jones S, Greenwood BM, Nash GB. Mechanisms of cytoadhesion of flowing, parasitized red blood cells from Gambian children with falciparum malaria. Am. J. Trop. Med. Hyg. 1995; 53(1):29-35.

7. Traore B, Muanza K, Looareesuwan S, Supavej S, Khusmith S, et al. Cytoadherence characteristics of Plasmodium falciparum isolates in Thailand developing severe symptoms. It is possible that binding to CSA receptors in the study population does not provoke harmful immune response. Moreover, the high percentage of cytoadhesion inhibition by CD36 mAb may reflect a strong selective pressure exerted by CD36 on the parasite isolates in this region. It is possible that P.falciparum parasites may use this receptor in vivo to promote parasite survival and immune evasion.

\section{ACKNOWLEDGMENT}

We would like to thank Artur Scherf, Unité de Biologie des Interactions Hôte-Parasite, Institut Pasteur and CNRS, Paris, France and Jurg Gysin, Unité de Parasitologie expérimentale, Université de la Méditerranée, Marseille, France for providing HLECs and training.

using an invitro human lung endothelial cells model. Am. J. Trop. Med. Hyg. 2000;62(1):38-44.

8. Cojean S, Jafari-Guemouri S, Le Bras J, Durand R. Cytoadherence characteristics to endothelial receptors ICAM-1 and CD36 of Plasmodium falciparum populations from severe and uncomplicated malaria cases. Parasite. 2008 b;15(2):163-9.

9. Chakravorty SJ, Hughes KR, Craig AG. Host response to cytoadherence in Plasmodium falciparum. Biochem Soc Trans. 2008;36(Pt 2):221-8.

10. Pouvelle B, Fusai T, Le'polard C and Gysin J. Biological and Biochemical Characteristics of Cytoadhesion of Plasmodium falciparum-Infected Erythrocytes to Chondroitin-4-Sulfate. Infecion and Immnity 1998;66(10):49504956.

11. Trager $\mathbf{W}$, and Jensen JB. Human malaria parasites in continuous culture. Science 1976;193:673-675

12. Pasvol G, Wilson RJ, Smalley ME, Brown J. Separation of viable schizont-infected red cells of Plasmodium falciparum from human blood. Ann Trop Med Parasitol. 1978; 72(1):87-8

13. Aitman TJ, Cooper LD, Norsworthy PJ, Wahid FN, Gray JK, et al. Malaria susceptibility and CD36 mutation. Nature 2000; 405(29):1015-1016.

14. Beeson JG, Ndungu F, Persson KE, Chesson JM, Kelly GL, Uyoga S, Hallamore SL, Williams TN, Reeder JC, Brown GV, Marsh K. Antibodies among men and children to placental-binding Plasmodium falciparum-infected erythrocytes that express var2csa. Am J Trop Med Hyg. 2007 $\mathrm{J} ; 77(1): 22-28$. 